\title{
CSF concentration gradients of monoamine metabolites in patients with hydrocephalus
}

\author{
Jan Malm, Bo Kristensen, Jan Ekstedt, Per Wester
}

\begin{abstract}
Concentration gradients of homovanillic acid (HVA), 5-hydroxyindoleacetic acid (5-HIAA), and 3-methoxy-4-hydroxyphenylglycol (MHPG), were assessed in 762 successive CSF fractions $(2 \mathrm{ml}$ lumbar CSF) from 15 patients with the adult hydrocephalus syndrome (AHS) and 11 patients with hydrocephalus of other causes (mixed group). A mean volume of 49.6 (SD 11.8) $\mathrm{ml} \mathrm{CSF} \mathrm{was} \mathrm{removed} \mathrm{in}$ the AHS group and $56.4(10.2) \mathrm{ml}$ in the mixed group. The CSF was collected with a specially designed carousel fraction collector and the corresponding CSF dynamics were continuously registered by a constant pressure CSF infusion method. Pronounced gradients in CSF HVA and CSF 5-HIAA were seen in both patient groups in the first $25 \mathrm{ml}$ of CSF removed. The concentration curves levelled off, despite the removal of larger amounts of CSF and stabilised at about twice the initial concentrations. This phenomenon has not been described before. Concentrations of HVA and 5HIAA in the first CSF fraction correlated strongly with concentrations in fractions up to about $40 \mathrm{ml}$. A positive correlation between the first fraction of CSF HVA and CSF 5-HIAA concentrations and CSF outflow conductance was found in the AHS group. There was no gradient in MHPG. It is suggested that the rostrocaudal gradients in CSF HVA and 5HIAA may be explained by a downward flow of CSF along the spinal cord with absorption of metabolites occurring during passage. Mixing of CSF from different CSF compartments, extraventricular production sites of CSF, clearance of metabolites to venous blood or extracellular fluid, and CSF outflow conductance are probably important determinants of the plateau phase in patients with hydrocephalus. It is concluded that lumbar CSF does not exclusively reflect the concentrations of HVA, 5-HIAA, or MHPG in the ventricles. It should be noted that these results obtained in patients with hydrocephalus may not be applicable to other groups of patients or normal subjects.
\end{abstract}

(F Neurol Neurosurg Psychiatry 1994;57:1026-1033)

Many neurological and psychiatric disorders are associated with disturbances in the neurotransmission of biogenic amines. ${ }^{1-6}$ Treatment of certain disorders is performed by stimulating neurotransmitter synthesis or by stimulating or blocking presynaptic or postsynaptic monoamine receptors. The monoamine systems are located at different anatomical sites in the human brain. The highest concentrations of dopamine are found in the basal ganglia, of noradrenaline in the hypothalamus, and of serotonin in the subcortical regions. ${ }^{7}$ There is a correlation between transmitter concentration at these specific topographic origins and ventricular CSF. ${ }^{8}$ In humans, however, the use of ventricular CSF, brain biopsy, or microdialysis of the extracellular fluid are possible only during certain neurosurgical operations or at necropsy.

Lumbar puncture is the most important and widely used diagnostic tool in the study of monoamine metabolite concentrations and findings in lumbar CSF are commonly assumed to be similar to those in ventricular CSF. This assumption is supported by rostrocaudal CSF gradients ${ }^{9-12}$ - that is, the finding of decreasing concentrations of substances in the spinal subarachnoid space the further from the brain the CSF is removed. Rostrocaudal gradients of HVA and 5-HIAA, and to a lesser extent, of MHPG, have been described (table 1). ${ }^{13-25}$ Bulk flow of CSF is directed from the ventricles towards the cerebral subarachnoid space via the basal cisternae but the direction and amount of spinal CSF flow are unclear, and CSF may even be a "stagnant backwater." 26 Thus the assumption that monoamine metabolite concentrations found in lumbar CSF represent those in ventricular CSF may not hold true.

In this study, a method for standardised sampling of large volumes of lumbar CSF was used in a prospective series of 26 patients, investigated because of hydrocephalus. The rostrocaudal gradients for HVA, 5-HIAA, and MHPG are presented as well as factors that may contribute to differences in the metabolite concentrations between ventricular and lumbar CSF. Different CSF spinal flow options are discussed.

\section{Materials and methods}

PATIENTS AND CLINICAL INVESTIGATION

During February 1990-May 1991, 146 patients were studied in a CSF hydrodynamic investigation ${ }^{27}$ at the neurological department. Of these, 27 (17 men, 10 women; mean age (SD) $72.6(6.4)$ years) satisfied the inclusion 
Table 1 Earlier published studies concerning CSF gradients of monoamine metabolites. Monoamine metabolite concentrations are presented as a ratio between the concentration in the first and last CSF fraction

\begin{tabular}{|c|c|c|c|c|c|c|c|c|c|c|c|c|}
\hline $\begin{array}{l}\text { Reference } \\
\text { No }\end{array}$ & $\begin{array}{l}\text { CSF } \\
\text { removed } \\
(\mathrm{ml})\end{array}$ & $\begin{array}{l}\text { Fractions } \\
\text { (No) }\end{array}$ & ml/fraction & Bedrest & Fasting & Diagnosis & $\begin{array}{l}\text { MHPG } \\
\text { (ratio) }\end{array}$ & $\begin{array}{l}\text { 5-HIAA } \\
\text { (ratio) }\end{array}$ & $\begin{array}{l}\text { HVA } \\
\text { (ratio) }\end{array}$ & $\begin{array}{l}\text { Body } \\
\text { position }\end{array}$ & $\begin{array}{l}\text { Patient } \\
\text { (No) }\end{array}$ & Others \\
\hline $\begin{array}{l}13 \\
14 \\
15 \\
16\end{array}$ & $\begin{array}{l}40 \\
12 \\
60 \\
\text { a } 20 \\
\text { b } 20\end{array}$ & $\begin{array}{l}4 \\
4 \\
2 \\
10 \\
2\end{array}$ & $\begin{array}{l}10 \\
3 \\
6 \\
2 \\
2\end{array}$ & $\begin{array}{l}\text { NM } \\
\text { Yes } \\
\text { NM } \\
\text { NM }\end{array}$ & $\begin{array}{l}\text { NM } \\
\text { Yes } \\
\text { Yes } \\
\text { NM }\end{array}$ & $\begin{array}{l}\text { VND } \\
\text { VPD } \\
\text { VND } \\
\text { MS + controls }\end{array}$ & $\begin{array}{l}1 \cdot 0 \\
\approx 1 \cdot 0 \\
\overline{1} \cdot 1\end{array}$ & $\begin{array}{l}1 \cdot 2 \\
\approx 1 \cdot 7 \\
1 \cdot 3 \\
1 \cdot 75\end{array}$ & $\begin{array}{l}1.7 \\
\approx 1.9 \\
\frac{1}{1.5}\end{array}$ & $\begin{array}{l}\text { Sitting } \\
\text { Sitting } \\
\text { NM } \\
\text { LRP }\end{array}$ & $\begin{array}{l}9 \\
28 \\
72 \\
40\end{array}$ & PEG \\
\hline $\begin{array}{l}17 \\
18\end{array}$ & $\begin{array}{l}38 \\
40-50\end{array}$ & $\begin{array}{l}3 \\
5\end{array}$ & $\begin{array}{l}5 \\
10\end{array}$ & $\begin{array}{l}\text { Yes } \\
\text { NM }\end{array}$ & $\begin{array}{l}\text { NM } \\
\text { NM }\end{array}$ & $\begin{array}{l}\text { VND } \\
\text { VND }\end{array}$ & $\frac{1 \cdot 1}{-}$ & $\overline{\text { Increase }}$ & $\overline{\text { Increase }}$ & $\begin{array}{l}\text { LRP } \\
\text { NM }\end{array}$ & $\begin{array}{l}15 \\
8\end{array}$ & $\begin{array}{l}\text { Neurosurgical } \\
\text { patient during } \\
\text { anaesthesia }\end{array}$ \\
\hline $\begin{array}{l}19 \\
20 \\
21 \\
22 \\
23 \\
24 \\
25 \\
\text { Present } \\
\text { study }\end{array}$ & $\begin{array}{l}15-24 \\
42 \\
19 \\
36 \\
15 \\
\text { NM } \\
\text { NM } \\
28-82\end{array}$ & $\begin{array}{l}4 \\
7 \\
3 \\
3 \\
2 \\
2 \\
2 \\
14-41\end{array}$ & $\begin{array}{l}2 \cdot 5 \\
6 \\
2 \\
12 \\
8 \\
\text { NM } \\
3-4 \\
2\end{array}$ & $\begin{array}{l}\text { NM } \\
\text { Yes } \\
\text { Yes } \\
\text { Yes } \\
\text { NM } \\
\text { Yes } \\
\text { NM } \\
\text { No }\end{array}$ & $\begin{array}{l}\text { NM } \\
\text { Yes } \\
\text { NM } \\
\text { NM } \\
\text { NM } \\
\text { No } \\
\text { Yes } \\
\text { No }\end{array}$ & $\begin{array}{l}\text { VND, VPD } \\
\text { VND } \\
\text { VPD } \\
\text { Schizophrenia } \\
\text { VND } \\
\text { VND } \\
\text { VND } \\
\text { Hydrocephalus }\end{array}$ & $\begin{array}{l}- \\
\overline{-} \\
\frac{1 \cdot 1}{-} \\
\frac{1}{1}\end{array}$ & $\begin{array}{l}\text { Increase } \\
2 \cdot 4 \\
1 \cdot 8 \\
1 \cdot 56 \\
2 \cdot 1 \\
2 \\
\approx 1 \cdot 4 \\
2\end{array}$ & $\begin{array}{l}\text { Increase } \\
\text { Increase } \\
1 \cdot 8 \\
1 \cdot 87 \\
3 \cdot 1 \\
=1 \cdot 5 \\
2\end{array}$ & $\begin{array}{l}\text { Sitting } \\
\text { NM } \\
\text { LRP } \\
\text { Sitting } \\
\text { NM } \\
\text { Sitting } \\
\text { Lying, Supine }\end{array}$ & $\begin{array}{l}3 \\
14 \\
18 \\
\text { NM } \\
10 \\
\text { NM } \\
35 \\
26\end{array}$ & $\begin{array}{l}\text { PEG } \\
\text { PEG }\end{array}$ \\
\hline
\end{tabular}

$\mathrm{NM}=$ Not mentioned; VND = various neurological diseases; VPD = various psychiatric diseases; LRP = lateral recumbent position; PEG = pneumoencephalography; MS = multiple sclerosis.

criteria for this study-namely, (1) hydrocephalus verified by CT; (2) clinical suspicion of the adult hydrocephalus syndrome (AHS); (3) no obvious contraindications to an extensive CSF tap.

At the time of inclusion, 24 of the 27 patients had disturbance of gait, alone or in combination with dementia or incontinence, and two had focal neurological signs, two complained of headache, one of vertigo, and two were asymptomatic.

All patients underwent the following laboratory investigations to determine the diagnosis and to exclude reversible and treatable causes of dementia: full blood count; urine analysis; erythrocyte sedimentation rate; serum electrolytes; tests of hepatic, renal, and thyroid function; blood glucose; antinuclear antibodies; serum cholesterol and triglyceride concentrations; syphilis and Borrelia serology; plasma protein electrophoresis; serum B12/folic acid; CSF protein and cell count. CT and, usually, MRI were also included.

After investigation, the 27 patients were categorised as follows: the adult hydrocephalus syndrome ${ }^{5}$ (gait disturbance, dementia and/or incontinence, dilated ventricles, and no obvious cause such as subarachnoid haemorrhage, meningitis, or trauma), 15 patients; multi-infarction dementia, ${ }^{28}$ four; Alzheimer dementia (NINDS-ARDRAS criteria, $)^{29}$ one; idiopathic intracranial hyperten-

Table 2 Characteristics of the AHS and mixed patient groups

\begin{tabular}{|c|c|c|c|}
\hline & $\begin{array}{l}A H S \\
(n=15)\end{array}$ & $\begin{array}{l}\text { Mixed } \\
(n=11)\end{array}$ & $\begin{array}{l}\text { All patients } \\
(n=26)\end{array}$ \\
\hline \multicolumn{4}{|l|}{ Physical measurements: } \\
\hline $\begin{array}{l}\text { Age (y) } \\
\text { A }\end{array}$ & $73.6(3.9)$ & $71 \cdot 2(8 \cdot 8)$ & $72 \cdot 0(8 \cdot 3)$ \\
\hline Sex (male/female) & $10 / 5$ & & $17 / 9$ \\
\hline Length (m) & $1 \cdot 7(0 \cdot 1)$ & $1 \cdot 7(0 \cdot 1)$ & $1.7(0 \cdot 1)$ \\
\hline Weight (kg) & $72 \cdot 3(11 \cdot 5)$ & $63.4(14.4)$ & $68 \cdot 7(13 \cdot 2)$ \\
\hline $\begin{array}{l}\text { Body mass index }\left(\mathrm{kg} / \mathrm{m}^{3}\right) \\
\text { Clinical }\end{array}$ & $25 \cdot 7(3 \cdot 4)$ & $22 \cdot 6(3 \cdot 3)$ & $24 \cdot 4(3 \cdot 6)$ \\
\hline $\begin{array}{l}\text { Clinical variables: } \\
\text { Duration of disease (months) }\end{array}$ & \\
\hline Mini-mental state ${ }^{2}$ (points) & $27(18)$ & $35(19)$ & 31 (19) \\
\hline Haschinski ischaemic scale ${ }^{53}$ (points) & $\begin{aligned} & 22.9(3.4)(3) \\
& 2.4(2.1)\end{aligned}$ & $\begin{array}{r}20 \cdot 8(9.2) \\
4.3(5.1)\end{array}$ & $\begin{array}{r}21 \cdot 7(7 \cdot 3) \\
3.3(3.6)\end{array}$ \\
\hline \multicolumn{4}{|l|}{ CSF hydrodynamic variables: } \\
\hline CSF removal (ml) & $49 \cdot 6(11 \cdot 8)$ & $56 \cdot 4(10 \cdot 2)$ & $52.5(11.5)$ \\
\hline CSF pressure $(\mathrm{kPa})$ & $1.6(0.4)$ & $1.8(0.8)$ & $1.7(0.6)$ \\
\hline Conductance $\left(\mathrm{mm}^{3} / \mathrm{kPa} \times \mathrm{s}\right)$ & $9.8(3.5)$ & $13.7(7 \cdot 3)$ & $11 \cdot 7(5 \cdot 5)$ \\
\hline CSF formation rate $\left(\mathrm{mm}^{3} / \mathrm{s}\right)$ & $7 \cdot 1(2 \cdot 1)$ & $8 \cdot 5(2 \cdot 0)$ & $7 \cdot 7(2 \cdot 2)$ \\
\hline
\end{tabular}

Values are means $(\mathrm{SD})$ sion (increased CSF pressure, unknown cause), ${ }^{30}$ one; alcoholic dementia (daily abuse for many years, no other cause), one; hydrocephalus of unknown cause, five. According to the diagnosis, patients were categorised as two groups: AHS (15 patients) or mixed (12 patients) groups. One patient in the mixed group was excluded because of a non-functioning lumbar puncture needle.

Table 2 summarises the characteristics of the two groups. There were no significant differences concerning physical, clinical, or CSF hydrodynamic variables between the AHS and mixed patient groups (Student's $t$ test). Two patients were taking benzodiazepines, two antidepressants, and another two anticholinergic drugs (terodiline). None was on neuroleptic medication. Data on CSF from these patients did not differ from the rest of the study group.

Consent for all aspects of the study was obtained from all the patients after explanation of the investigation procedure and possible risks.

\section{CSF HYDRODYNAMIC STUDIES}

The CSF hydrodynamic studies were performed according to Ekstedt. ${ }^{27}$ Briefly, at 0800 , after 12 hours of bed rest but without fasting, two needles were inserted in the L3L4 interspace by a very experienced investigator. The patient was then allowed to lie supine with the zero pressure reference level at the cranial sagittal centre. The needles were connected to pressure transducers by means of plastic tubes filled with artificial CSF. At application, loss of CSF was between $0 \cdot 5-2 \cdot 0$ $\mathrm{ml}$ in each patient. Pressure of CSF was continuously recorded via one of the needles. The other needle could be used for infusion of artificial CSF or drainage and CSF sampling via a three way tap (see later). The CSF resting pressure $\left(\mathbf{P}_{\mathrm{cl}}\right)$ was measured when the resting recording had been stable for at least $10 \mathrm{~min}-$ utes. Thereafter, the CSF sampling started (see later). The examination ended with determination of the conductance $\left(G_{o p}\right.$; the inverse of resistance to CSF outflow). This was done by applying a number of different 
pressures to the CSF space while recording the resulting inflow of artificial CSF. Thus within a few minutes a stable flow at a stable pressure was obtained. Usually, three different pressure/flow values were sought for each patient. The volume accounting method was used to calculate the pressure/flow relation. The slope for the pressure/flow values is equal to $\mathrm{G}_{\mathrm{op}}$.

\section{CSF SAMPLING}

The needle was connected to a plastic tube that ended with an injection needle, the point of which was fixed at a height of the zero reference level for the pressure measurements. The point of the needle was adjusted to $1 \mathrm{~cm}$ above one of the 12 test tubes of a specially designed carousel fraction collector, placed on a digital precision balance. An electronic device rotated the carousel $1 / 12$ of a turn each time the balance recorded a preset weight increase from the moment of the last change of test tube. A $2 \mathrm{~g}(=2 \mathrm{ml})$ weight increase was used but any value could be chosen. Immediately a test tube was filled, it was placed in the freezer $\left(-70^{\circ} \mathrm{C}\right)$. For the first test tube a value equal to the amount of artificial CSF in the plastic tubing was chosen and this fraction of CSF was discarded. The CSF pressure was about $0.2 \mathrm{kPa}$ during the collection period, well below the pressure in the sagittal sinus. Thus when the CSF pressure had stabilised at this level, no CSF could escape through the arachnoidal villi into the sagittal sinus. The rate of CSF outflow thus corresponded to the CSF formation rate.

\section{ASSESSMENT OF MONOAMINE}

\section{CONCENTRATIONS}

Concentrations of 3-methoxy-4-hydroxyphenylglycol (MHPG), homovanillic acid (HVA), and 5-hydroxyindoleacetic acid (5HIAA) were determined simultaneously by reversed phase isocratic liquid chromatography with electrochemical detection essentially as described elsewhere. ${ }^{3132}$ Briefly, to each $90 \mu \mathrm{l}$ of CSF, $10 \mu \mathrm{l}$ of $1 \mathrm{M}$ perchloric acid, $9 \mathrm{mM}$ L-cysteine, and $0.5 \mathrm{mM}$ isoproterenol (internal standard) were added. The samples were vortexed, centrifuged at $48000 \mathrm{~g}$ for 30 minutes at $4^{\circ} \mathrm{C}$ and $20 \mu \mathrm{l}$ was then directly injected into the chromatographic system. The isocratic mobile phase, with a flow rate of $0.28 \mathrm{ml} / \mathrm{minute}$ consisted of 100 $\mathrm{mM} \mathrm{Na} \mathrm{N}_{2}$ EDTA, $0.334 \mathrm{mM}$ octylsulphate: $5 \cdot 5 / 94.5 \%(\mathrm{v} / \mathrm{v})$ acetonitrile/water at a $\mathrm{pH}$ of $2 \cdot 35$. The stationary phase consisted of a $250 \times 2.0 \mathrm{~mm}$ stainless steel narrow bore column packed with Nucleosil C-18.5 $\mu \mathrm{m}$ from Macherey-Nagel (Düren, Germany), the column temperature was controlled by means of a plastic jacket coupled to a water thermostat that was set at $25^{\circ} \mathrm{C}$. The substances were detected electrochemically with a BAS 3 electrochemical detector (Bioanalytical systems, West Lafayette, $\mathrm{N}$, USA), operated at a potential of $0.75 \mathrm{mV} v$ an $\mathrm{Ag} / \mathrm{AgCl}$ reference electrode. The detector was coupled to an integrator (model SP 4400, Spectraphysics, San Jose, CA, USA). The coefficient of varia- tion (CV) showed an average value of $1.8 \%$ for standards and $2 \cdot 1 \%$ for CSF samples. A linear response was found for the substances in the range of $0 \cdot 1-256 \mathrm{pmol}(r>0.999)$. The detection limit, defined as a ratio of peak height to noise greater than 2, varied between 2 and 5 pmol with the equipment used. Variation (CV) showed an average value of $1.8 \%$ for standards and $2 \cdot 1 \%$ for CSF samples.

\section{STATISTICAL ANALYSIS}

Statistical analyses were conducted with the JMP program for the Macintosh computer. ${ }^{33}$ Comparisons of physical, clinical, and CSF hydrodynamic variables (table 2 ) between the AHS and the mixed groups were evaluated by Student's unpaired $t$ test. Linear regression analyses between physical, clinical, and CSF hydrodynamic variables $v$ the first CSF fraction of the CSF metabolites were performed where the regressors were tested in the models with a $t$ test $(\mathrm{HO}=0)$ and regarded as statistically significant when the corresponding $p$ value was below $0 \cdot 05$. The concentrations of transmitter metabolites were plotted against CSF fractions with $95 \%$ confidence intervals.

\section{Results}

There were no serious adverse events during the CSF hydrodynamic investigation or removal of CSF. The duration of the CSF pressure recording was 43.0 (SD 10.9) minutes in the AHS and 44.9 (14.9) minutes in the mixed group. The duration of the drain, where the CSF pressure is lowered by passive removal of CSF, was $66.8(20.4)$ minutes in the AHS and 63.7 (21.2) minutes in the mixed group. The estimation of CSF formation rate started when the CSF pressure had stabilised at $0.2(0.2) \mathrm{kPa}$ in both groups. The duration of the CSF formation rate appraisal was $35.4(16 \cdot 7)$ minutes in the AHS and $42 \cdot 2$ (19.7) minutes in the mixed group. $49 \cdot 6$ $(11.8) \mathrm{ml} \mathrm{CSF}$ was collected in the AHS and $56.4(10.2) \mathrm{ml}$ in the mixed group. There were. no significant differences in these variables between the AHS and mixed groups.

Mean values of CSF homovanillic acid (HVA) concentrations were plotted against CSF fractions in the AHS (fig 1A) and mixed group (fig 1B). CSF concentrations are presented as a ratio of the first CSF fraction to compensate for interindividual variations of initial CSF HVA values. A similar pattern of increasing HVA concentrations was found during the first $25 \mathrm{ml}$ in both the AHS and mixed groups. In subsequent $(27-59 \mathrm{ml})$ fractions, a plateau was reached with no further increase in CSF HVA concentration.

Similarly, increased concentrations of 5HIAA were seen in the first $25 \mathrm{ml}$ in patients in both the AHS and mixed groups, although no further increase was seen in fraction 27-59 $\mathrm{ml}$ (fig 1C,D). No gradient of CSF MHPG concentration was seen in either the AHS or mixed groups (fig $1 \mathrm{E}, \mathrm{F}$ ).

Figure $2 \mathrm{~A}$ shows the relation between the first fraction of CSF HVA concentration and 
Figure 1 CSF gradients of $H V A$, 5-HLAA, and MHPG in the AHS ( $n=$ 15) and mixed patient $(n=11)$ groups. Concentrations are presented as a ratio of the first CSF fraction (mean value and $95 \%$ confidence intervals). (A) HVA in AHS group; the median and ranges in CSF fraction Nos 1 and 15 were 1 : $200 \cdot 0(100 \cdot 0-919 \cdot 0)$ nmolll and 15: 432.0 (329-991) nmolll; (B) HVA in mixed group: 1: $239 \cdot 5(91 \cdot 0-469 \cdot 9)$ nmolll and 15: 410 (172.4-1353.4) nmolll; (C) 5-HIAA in $A H S$ group; $1: 79 \cdot 6$

(25.7-238.0) nmoll and 15: $103 \cdot 4(33 \cdot 4-262 \cdot 0)$ nmolll (D) 5-HIAA in mixed group; $1: 64 \cdot 0$ (40.7-100.8) nmoll and 15: $128 \cdot 0(57 \cdot 5-358 \cdot 6)$ nmolll (E) MHPG in AHS group; 1: 43.1 $(21 \cdot 7-91 \cdot 5)$ nmolll and 15: 44.2 (26.4-90.0) nmolll; (F) MHPG in mixed group; $1: 45 \cdot 3$ $(22 \cdot 3-160 \cdot 8) \mathrm{nmol} / \mathrm{l}$ and 15: $42 \cdot 9(20 \cdot 9-108 \cdot 6)$ nmolll.
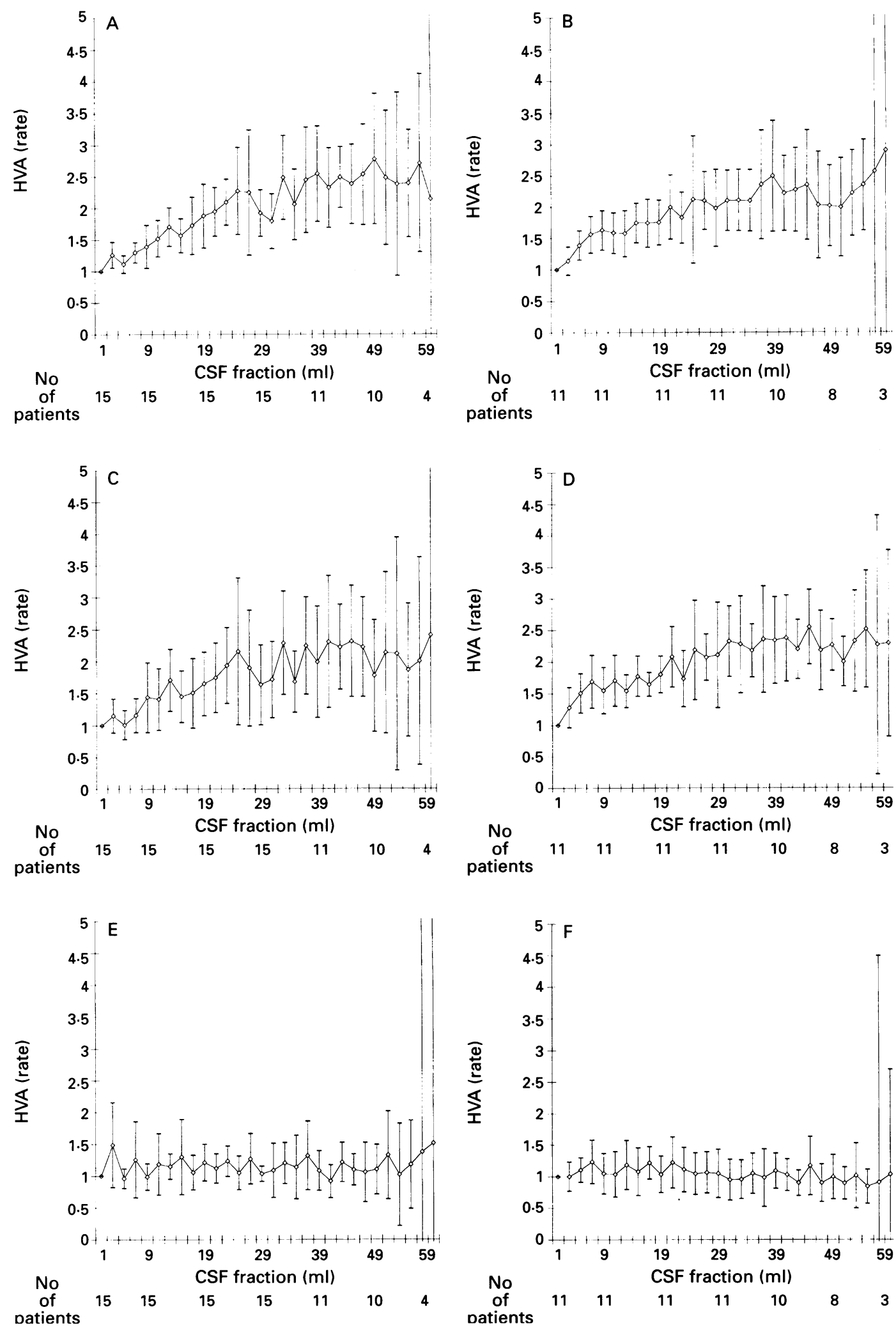

CSF outflow conductance. There was a positive correlation in the AHS group (fig $2 \mathrm{~A}$; linear regression; $r=0.64, p=0.014$ ) but not in the mixed group. There were also a positive correlation between CSF HVA concentration and CSF pressure (linear regression; $r=0.63$, $p=0.017$ ) in the AHS group only.

There was a positive correlation between the first fraction of CSF 5-HIAA concentration and CSF outflow conductance in the AHS group (fig 2B; linear regression; $r=$

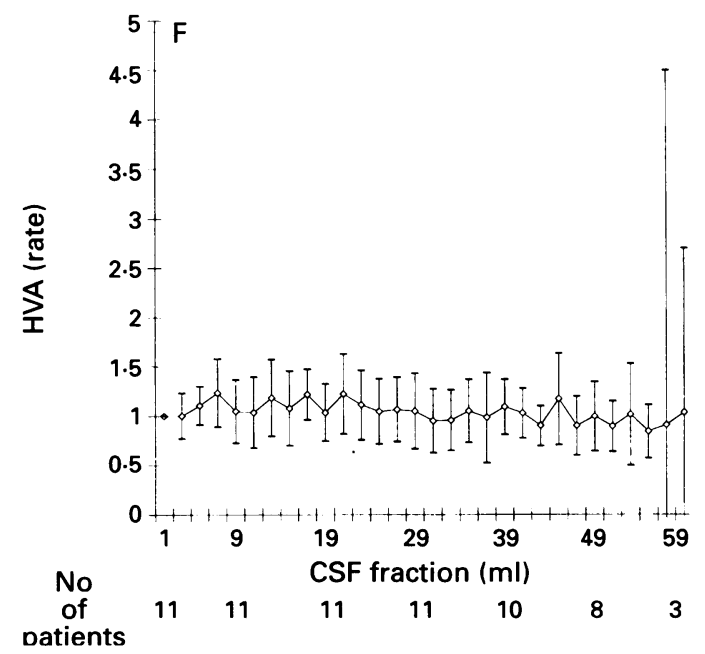

$0.62, \mathrm{p}<0.03)$, but not in the mixed group. A trend was found between CSF 5-HIAA and CSF pressure (linear regression; $r=0.49$, $\mathrm{p}=0.068$ ) in the AHS group.

There were no significant correlations between concentration of any of the monoamine metabolites in the first CSF fraction $v$ the physical or clinical variables described in table 2 in either the AHS or the mixed group. There were no significant correlations between the values for individual slope 
Figure 2 (A) Linear correlation between the first $C S F$ fraction of HVA and CSF outflow conductance in the AHS group; $(B)$ Linear correlation between the first CSF fraction of 5 HIAA and CSF outflow conductance in the AHS group.
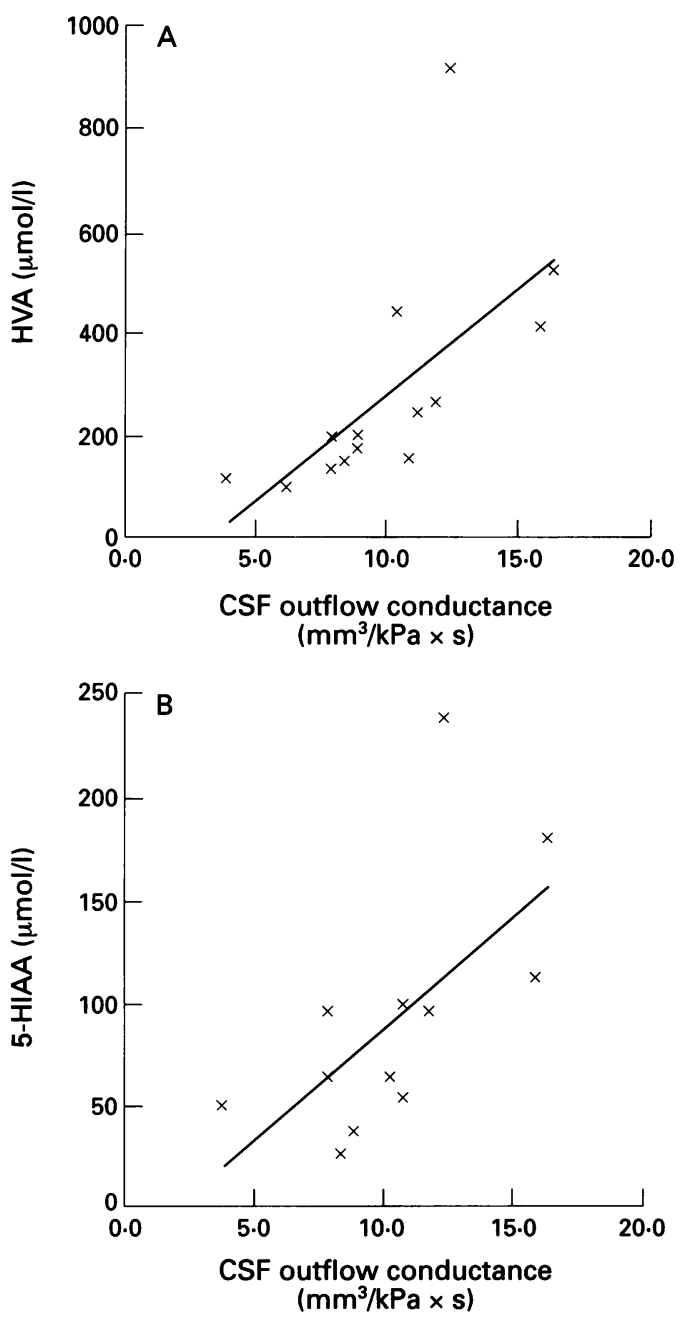

Table 3 Linear correlations between concentrations of $H V A$ and 5-HLAA in the first CSF fractions and sequential fractions

\begin{tabular}{|c|c|c|c|}
\hline \multirow{2}{*}{$\begin{array}{l}\text { CSF fraction } \\
\text { (ml CSF) }\end{array}$} & \multicolumn{2}{|c|}{ Correlation coefficient } & \multirow{2}{*}{$\begin{array}{l}\text { Patients } \\
\text { (No) }\end{array}$} \\
\hline & $H V A$ & 5-HLAA & \\
\hline 2 & $0.95^{\star \star \star}$ & $0 \cdot 81^{\star \star \star \star}$ & 22 \\
\hline 4 & $0 \cdot 86^{\star \star \star}$ & $0.62^{\star \star \star}$ & 25 \\
\hline 6 & $0.75^{\star \star \star}$ & $0 \cdot 40^{\star}$ & 26 \\
\hline 8 & $0.73^{\star \star \star}$ & $0 \cdot 22$ & 25 \\
\hline 10 & $0.87^{\star \star \star}$ & $0.73^{\star \star \star}$ & 25 \\
\hline 12 & $0 \cdot 85^{\star \star \star}$ & $0 \cdot 62^{\star \star \star}$ & 24 \\
\hline 14 & $0 \cdot 89^{\star \star \star}$ & $0 \cdot 69^{\star \star \star}$ & 23 \\
\hline 16 & $0.75^{\star \star \star}$ & $0.51^{\star \star}$ & 22 \\
\hline 18 & $0 \cdot 68^{\star \star \star}$ & 0.36 & 22 \\
\hline 20 & $0.69^{\star \star \star}$ & $0 \cdot 54^{\star \star}$ & 25 \\
\hline 22 & $0 \cdot 78^{\star \star \star}$ & $0.55^{\star \star}$ & 25 \\
\hline 24 & $0.50^{\star \star \star}$ & $0 \cdot 24$ & 24 \\
\hline 26 & $0.51^{\star \star \star}$ & $0 \cdot 30$ & 26 \\
\hline 28 & $0 \cdot 62^{\star \star \star}$ & $0 \cdot 37$ & 24 \\
\hline 30 & $0 \cdot 72^{\star \star \star}$ & $0 \cdot 46^{\star}$ & 22 \\
\hline 32 & $0.49^{\star}$ & 0.09 & 23 \\
\hline 34 & $0.57^{\star \star}$ & 0.08 & 21 \\
\hline 36 & 0.36 & $0 \cdot 14$ & 20 \\
\hline 38 & 0.34 & 0.14 & 21 \\
\hline 40 & 0.60 & $0 \cdot 17$ & 20 \\
\hline 42 & $0 \cdot 73^{\star \star \star}$ & $0 \cdot 48^{\star}$ & 20 \\
\hline 44 & 0.34 & 0.03 & 21 \\
\hline 46 & $0 \cdot 18$ & 0.02 & 21 \\
\hline 48 & 0.23 & $0 \cdot 24$ & 18 \\
\hline 50 & $0.52^{\star}$ & $0 \cdot 10$ & 15 \\
\hline 52 & 0.47 & $0 \cdot 10$ & 15 \\
\hline 54 & $0.93^{\star \star \star}$ & $0 \cdot 14$ & 14 \\
\hline 56 & 0.72 & 0.22 & 10 \\
\hline 58 & 0.43 & 0.56 & 6 \\
\hline
\end{tabular}

gradients of monoamine metabolites and CSF hydrodynamics, or the physical or clinical variables described in table 2 .

As there were no apparent differences in the concentration curves in the AHS and mixed groups (fig 1A, 1C $v 1 \mathrm{~B}, 1 \mathrm{D}$ ), patients were pooled in to a single group for further calculations. Table 3 shows the correlations between concentrations of HVA and 5-HIAA in the first $2 \mathrm{ml}$ of CSF removed and each subsequent CSF fraction. Correlations of HVA were high until about $34 \mathrm{ml} \mathrm{CSF} \mathrm{had}$ been removed. Highly significant correlations of 5-HIAA were noted until about $24 \mathrm{ml}$ of CSF had been removed and thereafter there were no correlations.

\section{Discussion}

The major finding in this prospective study of patients with communicating hydrocephalus was a rostrocaudal CSF gradient of the acidic monoamine metabolite (HVA and 5-HIAA) concentrations that levelled off to a plateau after withdrawal of more than $25 \mathrm{ml}$ of CSF (Fig 1 A-D). Also we confirmed our previous report of a positive linear relation between lumbar HVA and 5-HIAA concentrations $v$ CSF outflow conductance. ${ }^{5}$ A rostrocaudal gradient of HVA and 5-HIAA has been reported previously (table 1), but with a less pronounced slope of 5-HIAA compared with HVA in some instances. The plateau phase has not been described before, probably because of methodological faults in previous studies (table 1). Also, a limited number of patients, inconsistencies in diagnosis, removal of small quantities of CSF, or interference with analyses because of injection of gas, and inconsistencies in body position during lumbar puncture (table 1) may have influenced the results.

The following discussion (fig $3 \mathrm{~A}-\mathrm{C}$ ) is based on the fact that CSF HVA is formed mainly in the basal ganglia ${ }^{7}$ and the assumption that CSF HVA is an indicator of CSF flow. One has to take into consideration, however, the influence of formation, mixing, and clearance of CSF (as discussed in the second section), which are plausible confounding mechanisms in the model to be discussed.

GRADIENTS EXPLAINED BY SPINAL CSF FLOW? Little is known about the existence of an upward or downward spinal CSF flow in humans; this is probably the main obstacle in the interpretation of concentration gradients in the subarachnoid spinal space. According to fig 3, there are three principle possibilities of the spinal flow direction: downwards, upwards or to and fro (fig $3 \mathrm{~A}-\mathrm{C}$ ):

CSF flow downward (fig $3 A$ )

If the spinal CSF flow is directed downwards, CSF HVA from the ventricles moves via the basal cisternae towards the cortical space as well as towards the spinal compartment. This implies the existence of CSF absorption at the spinal level. A structure that closely resembles the arachnoidal villi associated with the spinal 

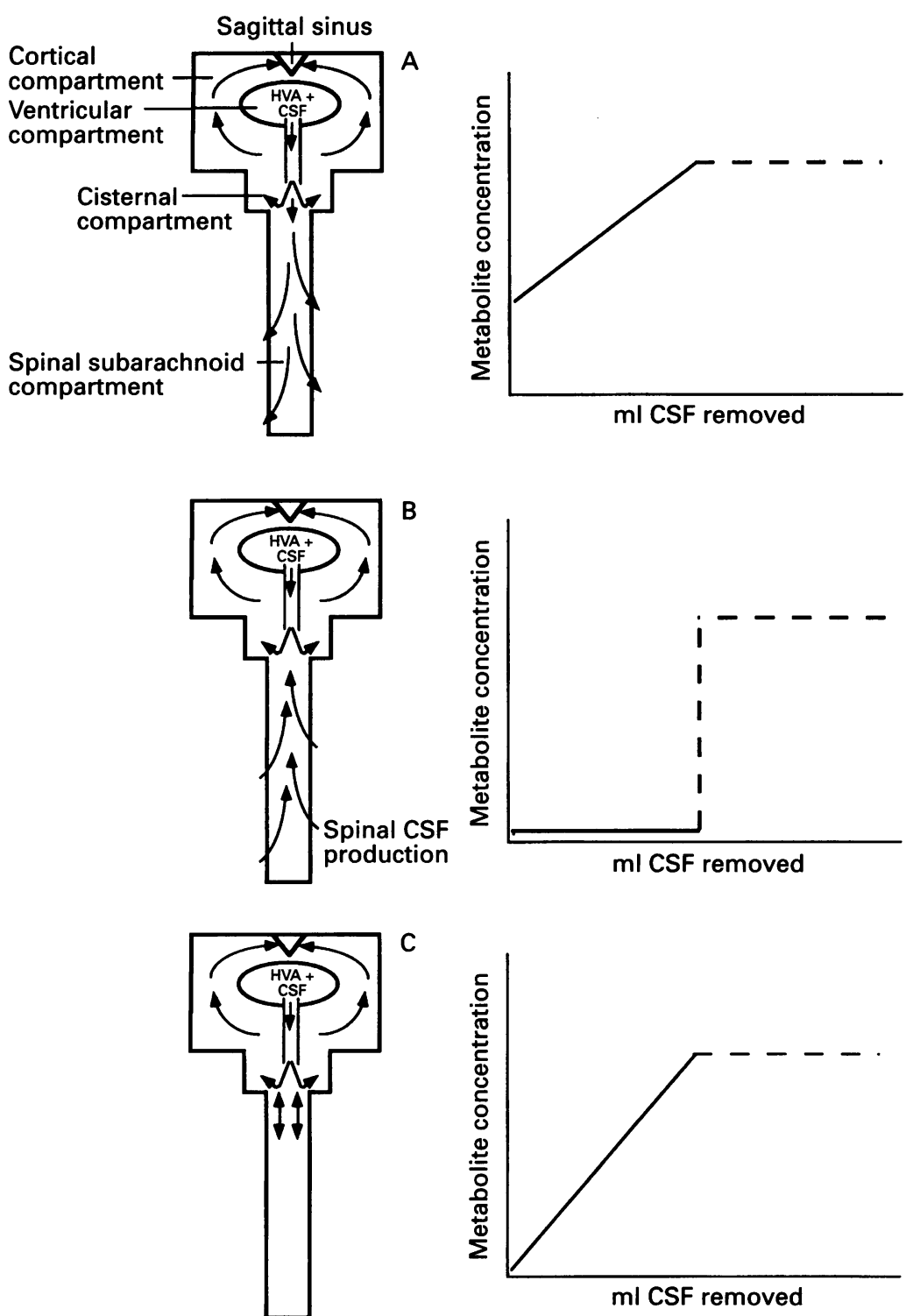

Figure 3 Directions of CSF flow. Schematic drawings of hypothetical models of CSF flow explaining different types of concentration curves. For further explanation, see discussion.
CSF flow to and fro (fig 3C)

In the absence of CSF spinal formation and spinal CSF absorption, there will be no net flow through the foramen magnum and the concentration curve of CSF HVA will be close to zero in the first fractions. Because of diffusion and the impelling forces of the spinal CSF (perpetual variations in volume during cardiac systole, respiration, talking, coughing, sneezing, straining, or changing body position), ${ }^{26}{ }^{37}$ there will be a to and fro motion of CSF between the spinal and supraspinal compartments. From zero, the concentrations of CSF HVA would steadily increase in ensuing fractions (fig 3C).

In conclusion, the rostrocaudal gradients of CSF HVA and CSF 5-HIAA may be predicted by a spinal CSF flow directed downwards, CSF absorption, and clearance of acidic metabolites at the spinal level. There was no rostrocaudal gradient of MHPG, which was an expected finding considering that the neutral glycol MHPG diffuses freely and rapidly across the blood-brain and bloodCSF barriers. ${ }^{338-40}$

\section{THE PLATEAU}

Most studies report a striking similarity between the ratio of maximum concentrations $v$ the base line concentrations of CSF HVA and CSF 5-HIAA. In the present study the ratio was about 2 in both 5-HIAA and HVA, which agrees with previous results (table 1). In studies in which monoamine concentrations in lumbar CSF have been compared with concentrations in CSF removed simultaneously from the ventricles, HVA and 5HIAA concentrations in the lateral ventricles have been estimated to be up to threefold to 10-fold those in lumbar CSF.93840-42 The ventriculolumbar gradients were $4: 1$ and $5: 1$, respectively, in nine patients with AHS. ${ }^{38}$ The plateau phase in later CSF fractions in this study, using a lumbar CSF tap technique, with a lower maximum ratio of CSF HVA and 5-HIAA compared with studies with simultaneous measurement from lumbar and ventricular CSF may be explained by some of the following mechanisms. These variables may also explain the increasing confidence intervals in the later CSF portions (fig $1 \mathrm{~A}-\mathrm{F}$ ).

\section{Mixing of CSF from different compartments}

When CSF pressure is lowered by CSF removal, as in this study, CSF in the system as well as newly formed CSF will flow towards the lumbar puncture needle. The initial fractions are composed of CSF from adjacent regions, both caudal and rostral to the lumbar puncture needle. As the drain continues, the spinal subarachnoid space is gradually emptied and the net CSF volume is replaced by dilatation of the extradural veins ${ }^{44}$ and CSF from the intracranial compartments. During this phase the CSF pressure declines and will fall below the sagittal sinus pressure. When this happens, CSF from the ventricles as well as CSF in the cortical subarachnoid space will flow towards the lumbar region. This implies a mixture of CSF from different 
compartments containing different concentrations of CSF monoamines in the lumbar spinal space. ${ }^{25}$ Emptying of the cortical sulcal CSF volume during the lumbar puncture is possible. ${ }^{45}$

\section{Different sites of CSF production}

CSF is generally considered to be mainly formed by the choroid plexus. Recent studies suggest, however, that up to $70 \%$ of the CSF may be formed in extraventricular compartments. ${ }^{46} 47$ This implies that CSF formed in the ventricles containing high concentrations of the monoamine metabolite HVA would be "diluted" when reaching the cisternae and the spinal compartment by CSF containing low concentrations.

\section{Clearance of metabolites to venous blood}

CSF HVA and CSF 5-HIAA are cleared by a probenecid sensitive system. ${ }^{48}$ The site of this system is unknown but the cortical subarachnoid space $^{49}$ and to a lesser extent the fourth ventricle ${ }^{50}$ and the spinal subarachnoid space ${ }^{51}$ have been proposed. Monoamine metabolites circulating with the CSF bulk flow will be continuously absorbed resulting in a gradual decrease in transmitter concentrations as the CSF travels down the spinal subarachnoid space.

\section{Clearance of metabolites to extracellular fluid}

Metabolite concentrations may also be lowered by diffusion from CSF to extracellular fluid along the CSF circulating pathway. The spinal cord has an extensive surface area across which diffusional loss of a monoamine metabolite may occur.

\section{CSF outflow conductance}

Disturbed hydrodynamics of CSF affect formation, mixing, and direction of flow of CSF and interrupt formation and clearance of monoamine metabolites. ${ }^{510}$ As confirmed in this study, a low CSF outflow conductance may facilitate the clearance of acidic substances. ${ }^{5}$

\section{Clinical implications}

In the present study there was good correlation between the initial lumbar and subsequent concentrations of CSF HVA and 5-HIAA respectively until $40 \mathrm{ml}$ of CSF had been removed (table 3 ). A similar result was described by Banki and Molnár, ${ }^{20}$ who removed CSF via the lumbar route and found a high correlation coefficient $(r=0.73)$ between the first and last fraction ( $42 \mathrm{ml} \mathrm{CSF}$ removed). In the present study, the positive correlations disappeared in the last CSF fractions. These fractions are not solely representative for ventricular CSF, and the impact of mixing and dilution of CSF and clearance of acidic metabolites on lumbar CSF HVA and 5-HIAA concentrations, as earlier discussed, could provide a reasonable explanation for this finding. A lumbar CSF tap could not be used to remove ventricular CSF exclusively; however, lumbar CSF HVA and 5-HIAA seem to be derived from the same sources as the fluid next to the brain, although not defined to any specific supraspinal compartment. Lumbar CSF MHPG does not reflect brain neurochemistry.

This study was supported by the Neurologiskt handikappades Riksförbund, Swedish Heart and Lung Foundation, King Gustaf V's 80th Anniversary Fund, Karl-Oskar Hanssons Foundation, and the Swedish Society of Medicine.

1 Davis K, Kahn R, Ko G, Davidson M. Dopamine in schizophrenia: a review and reconceptualization. $\mathrm{Am} \mathcal{J}$ Psychiatry 1991;148:1474-86.

2 McDonald W, Nemeroff C. Neurotransmitters and neuropeptides in Alzheimer's disease. Psychiatric Clin North Am 1991;14:421-41.

3 Davis B. Biogenic amines and their metabolites in body fluids of normal, psychiatric and neurological subjects. f Chromatogr 1989;466:89-218.

4 Gottfries C. Brain monoamines and their metabolites in dementia. Acta Neurol Scand (suppl) 1990;129:8-11.

5 Malm J, Kristensen B, Ekstedt J, et al. CSF monoamine metabolites, cholinesterases and lactate in the adult hydrocephalus syndrome (normal pressure hydrohydrocephalus syndrome (n) cephalus) related to CSF hydrodynamic paral Neurosurg Psychiatry 1991;54:252-9.

6 Andersson H, Roos B-E. 5-hydroxyindoleacetic acid in cerebrospinal fluid of hydrocephalic children. Acta Paediatr Scand 1969;58:601-8.

7 Wester P, Bergström U, Eriksson A, Gezelius C, Hardy J, Winblad B. Ventricular cerebrospinal fluid monoamine transmitter and metabolite concentrations reflect human brain neurochemistry in autopsy cases. $f$ Neurochem 1990;54:1148-1156.

8 Moir A, Ashcroft G, Crawford T, Eccleston D, Guldberg $H$. Cerebral metabolites in cerebrospinal fluid as a biochemical approach to the brain. Brain 1970;93:357-68.

9 Stanley $M$, Träskman-Bendz L, Dorovini Zis K. Correlations between aminergic metabolites simultaneously obtained from human CSF and brain. Life Sci ously obtained from

10 Garelis E, Young S, Lal S, Sourkes T. Monoamine metabolites in lumbar CSF: The question of their origin in relation to clinical studies. Brain Res 1974;79:1-8.

11 Wood JH. Neurochemical analysis of cerebrospinal fluid. Neurology 1980;30:645-51.

12 Wood JH, ed. Neurobiology of cerebrospinal fluid. New York: Plenum Press, 1980

13 Sjöström R, Ekstedt J, Änggård E. Concentration gradients of monoamine metabolites in human cerebrospinal fluid. F Neurol Neurosurg Psychiatry 1975;38:666-8.

14 Bertilson L, Ásberg M, Lantto O, et al. Gradients of monoamine metabolites and cortisol in cerebrospinal fluid of psychiatric patients and healthy controls. Psychiatry Res 1982;6:77-83.

15 Young S, Gauthier S, Anderson G, Purdy W. Tryptophan, 5 -hydroxyindoleacetic acid and indoleacetic acid in human cerebrospinal fluid: interrelationships and the influence of age, sex, epilepsy and anticonvulsant drugs. influence of age, sex, epilepsy and anticonvuls
$\mp$ Neurol Neurosurg Psychiatry 1980;43:438-45.

16 Andersen O, Johansson B, Svennerholm L. Monoamine metabolites in successive samples of spinal fluid. Acta Neurol Scand 1981;63:247-54.

17 Ziegler M, Wood J, Lake C, Kopin I. Norepinephrine and 3-methoxy-4-hydroxyphenyl glycol gradients in human cerebrospinal fluid. Am f Psychiatry 1977;134:565-8.

18 Tyce G, Messick J, Yaksh T, et al. Amine sulfate formation in the central nervous system. Fed Proc 1986;45: 2247-53.

19 Siever L, Kraemer H, Sack R, et al. Gradients of biogenic amine metabolites in cerebrospinal fluid. Dis Nerv Syst 1975;36:13-6.

20 Banki C, Molnár G. Cerebrospinal fluid 5-hydroxyindoleacetic acid as an index of central serotonergic processes. Psychiatry Res 1981;5:23-32.

21 Gateless D, Stanley M, Träskman-Bendz L, Gilroy J. The influence of the lying and sitting positions on the gradients of 5-HIAA and HVA in lumbar cerebrospinal fluid Biol Psychiatry 1984;19:1585-9.

22 Scheinin M, Seppala T, Koulu M, Linnoila M Determination of conjugated dopamine in cerebrospinal fluid from humans and non-human primates with high performance liquid chromatography using electrochemical detection. Acta Pharmacol Toxicol 1984;55:88-94.

23 Jakupcevic Z, Lackovic Z, Stefoski D, Bulat $M$ Nonhomogeneous distribution of 5-hydroxyindoleacetic acid and homovanillic acid in the lumbar cerebrospinal fluid of man. F Neurol Sci 1977;31:165-71.

24 Eccleston D, Ashcroft G, Crawford T, et al. Effect of tryptophan administration on 5-HIAA in cerebrospinal fluid in man. $₹$ Neurol Neurosurg Psychiatry 1970;33:269-72.

25 Garelis E, Sourkes T. Use of cerebrospinal fluid drawn at pneumoencephalography in the study of monoamine pneumoencephalography in the study of monoamine
metabolism in man. $\mathcal{f}$ Neurol Neurosurg Psychiatry 1974; 37:704-10.

26 Davson H, Welch K, Segal M. Physiology and pathophysiology of the cerebrospinal fluid. Edinburgh: Churchill Livingstone, 1987:1013.

27 Ekstedt J. CSF hydrodynamic studies in man. I. Method of constant pressure CSF infusion. F Neurol Neurosurg Psychiatry 1977;40:105-19. 
28 American Psychiatric Association. Diagnostic and statistical manual of mental disorders. 3rd ed. Washington DC: American Psychiatric Association, 1980.

29 McKhann G, Drachman D, Folstein M, et al. Clinical diagnosis of Alzheimer's disease: Report of the NINCDS-ARDRA Work Group under the auspices of Department of Health and Human Services Task force Department of Health and Human Services Task
on Alzheimer's disease. Neurology 1984;34:939-44.

30 Malm J, Kristensen B, Markgren P, Ekstedt J. CSF hydrodynamics in idiopathic intracranial hypertension: A long term study. Neurology 1992:42:851-8.

31 Wester P, Gottfries J, Winblad B. Simultaneous liquid chromatographic determination of seventeen of the major monoamine neurotransmitters, precursors and metabolites. I. Optimization of the mobile phase using factorial designs and a computer program to predict chromatograms. $\mathcal{f}$ Chromatogr 1987;415:275-88.

32 Wester P, Gottfries J, Winblad B. Simultaneous liquid chromatographic determination of seventeen of the major monoamine neurotransmitters, precursors and metabolites. II. Assessment of human brain cerebrospinal fluid concentrations. $\mathcal{f}$ Chromatogr 1987;415: 275-88.

33 Sall J, $\mathrm{Ng} \mathrm{K}$, Hecht M. FMP. Cary: SAS Institute Inc,

34 Maillot C. The perispinal space. $f$ Neuroradiol 1991;18: 18-3

35 Sato O, Asai T, Amano Y, et al. Extraventricular origin of the cerebrospinal fluid: formation rate quantitatively measured in the spinal subarachnoid space of dogs. Neurosurgery 1972;36:276-82.

36 Lux E, Fenstermacher J. Cerebrospinal fluid formation in ventricles and spinal subarachnoid space of the rhesus monkey. $\mathcal{F}$ Neurosurg 1975;42:674-8.

37 Ekstedt J. How does the cerebrospinal fluid reflect the function of the brain? Some notes on the physiology of the CSF. In: Perris C, Struwe G, Jansson B, eds. IIIrd World Congress of Biological Psychiatry. Stockholm: Elsevier/North-Holland Biomedical Press, 1981:329Elsevier.

38 Gjerris A, Werdelin L, Gjerris $\mathrm{P}$, et al. CSF-amine metabolites in depression, dementia and in controls. Acta Psychiatr Scand 1987;75:619-28.

39 Chase $\mathrm{T}$, Gordon $\mathrm{E}, \mathrm{Ng} \mathrm{L}$. Norepinephrine metabolism in the central nervous system of man: studies using 3methoxy-4-hydroxyphenylethylene glycol levels in cerebrospinal fluid. $\mathcal{F}$ Neurochem 1973;21:581-7.
40 Karoum F, Moyer-Schwing J, Potkin S, Jed R. Presence of free, sulfate and glucuronide conjugated 3-methoxy-4hydroxyphenylolycol (MHPG) in human brain cerebrospinal fluid and plasma. Brain Res 1977;125:333-9.

41 Sourkes T. Enzymology and sites of action of monoamines in the cental nerous system. Adv Neurol 1973:2:13-35. in the central nervous system. Adv Neurol $1973 ; 2: 13-35$.

42 Karoum F, Gillin J, Wyatt R, Costa E. Mass-fragmentography of nanogram quantities of biogenic amine graphy of nanogram quantities of biogenic amine brain. Biomed Mass Spectrometry 1975;2:183-9.

43 Ashcroft G, Crawford T, Eccleston D, et al. 5-hydroxyindole compounds in the cerebrospinal fluid of patients with psychiatric or neurological diseases. Lancet 1966;ii: 1049-52.

44 Fridén H, Ekstedt J. Volume/pressure relationship of the cerebrospinal space in humans. Neurosurgery 1983;13. 351-66.

45 Grant R, Condon B, Hart I, Teasdale G. Changes in intracranial CSF volume after lumbar puncture and their relationship to post-LP headache. $\mathfrak{f}$ Neurol Neurosurg Psychiatry 1991;54:440-2.

46 McComb G. Recent research into the nature of cerebrospinal fluid formation and absorption. $\mathcal{f}$ Neurosurg 1983;59:369-83.

47 Oreskovic D, Whitton P, Lupret V. Effect of intracranial pressure on cerebrospinal fluid formation in isolated brain ventricles. Neuroscience 1991;41:773-7.

48 Ebert M, Kartzinel R, Cowdry R, Goodwin F Cerebrospinal fluid amine metabolites and probenicid test. In: Wood J, ed. Neurobiology of cerebrospinal fluid. New York: Plenum Press, 1983:97-112.

49 Wolfson L, Katzman R, Escriva A. Clearance of amine metabolites from the cerebrospinal fluid: the brain as a "sink". Neurol Minneap 1972;22:402.

50 Ashcroft G, Dow R, Moir A. The active transport of 5 hydroxyindole-3-acetic acid and 3-methoxy-4-hydroxyphenylacetic acid from a recirculating perfusion system of the cerebral ventricles of the unanesthetised dog. of the cerebral ventricles of the

51 Van Der Poel F, Van Praag H, Korf J. Evidence for a probenicid-sensitive transport system of acid monoamine metabolites from the spinal subarachnoid space. Psychopharmacology (Berl) 1977;52:35-40.

52 Folstein MF, Folstein SE, McHugh PR. Mini-Menta State. F Psychiatr Res 1975;12:189-98.

53 Haschinski VC, Iliff LD, Zilhka E, et al. Cerebral blood flow in dementia. Arch Neurol 1975;32:632-7. 